\title{
ANALISIS POLA SEBARAN PARAMETER FISIKA AIR LAUT SEBAGAI DAYA DUKUNG USAHA BUDIDAYA TAMBAK IKAN DI KABUPATEN JEPARA, JAWA TENGAH
}

\author{
Arif Mustofa, Harminto Mulyo \\ Fakultas Sains dan Teknologi, Unisnu Jepara, Jepara Jawa Tengah, \\ Indonesia \\ Email: arifmustofa@unisnu.ac.id
}

Received October 2019, Accepted April 2020

\begin{abstract}
ABSTRAK
Faktor penting dalam usaha budidaya tambak adalah kualitas air laut yang sesuai dengan kebutuhan hewan budidaya. Media ini harus optimal semua parameternya. Pengukuran parameter fisik kualitas air laut dilakukan untuk menganalisis kesesuaian kondisi fisika air laut sebagai media budidaya sesuai daya dukung lingkungan perairan untuk usaha tambak. Sampel berupa air laut diambil dari 10 titik di sepanjang pantai Kabupaten Jepara dengan pengulangan masing-masing 3 kali. Analisa parameter fisika air laut yang diukur secara insitu adalah suhu, salinitas, dan kecerahan. Sedangkan total padatan tersuspensi dengan analisa sesuai prosedur pengukuran kandungan total zat padat tersuspensi berdasarkan SNI 06-6989.3-2004. Analisis daya dukung lingkungan dilakukan pada tiap titik dengan memberikan pembobotan terhadap parameter lingkungan perairan. Selanjutnya dikategorikan dalam sistem kelas, yaitu kelas S1 adalah tingkat sangat sesuai, kelas S2 adalah tingkat sesuai dan kelas S3 adalah tingkat tidak sesuai. Analisa menggunakan metode SIG untuk mendapatkan peta kesesuaian parameter kualitas air laut. Pengukuran parameter kualitas air di perairan Kabupaten Jepara mendapatkan data suhu sebesar $27,8-28,6^{\circ} \mathrm{C}$, salinitas sebesar $35,0-37,3$ ppt kecerahan sebesar $70-120 \mathrm{~cm}$ dan Total Suspended Solid (TSS) sebesar 48,60-64,40 mg/l. Sepanjang perairan pantai Kabupaten Jepara tidak ada yang masuk dalam kelas S1. Lokasi perairan yang masuk dalam kelas S2 perairan Kecamatan Kedung, Kecamatan Tahunan, Kecamatan Keling dan Kecamatan Donorojo. Sedangkan kelas S3 berada pada perairan Kecamatan Jepara, Kecamatan Mlonggo, Kecamatan Bangsri dan Kecamatan Kembang.
\end{abstract}

Kata kunci : Parameter, Fisika, Perairan, Budidaya, Tambak, Jepara

\section{ABSTRACT}

ANALYSIS OF SEA WATER PHYSICS PARAMETER DISTRIBUTION AS AN AQUACULTURE SUPPORT IN JEPARA REGENCY, CENTRAL JAVA. An important factor in pond aquaculture is the quality of sea water 
in accordance with the needs of cultivan aquaculture. This media must optimize all parameters. Measurement of physical parameters of seawater quality is carried out to analyze the suitability of the physical conditions of seawater as a culture medium in accordance with the carrying capacity of the aquatic environment for the pond business. Samples in the form of sea water were taken from 10 points along the coast of Jepara Regency with each repetition of 3 times. Analysis of seawater physics parameters measured in situ are temperature, salinity, and brightness. While the total suspended solids are analyzed according to the procedure for measuring the total content of suspended solids based on SNI 06-6989.3-2004. Environmental carrying capacity analysis is carried out at each point by giving a weighting to the parameters of the aquatic environment. Furthermore, it is categorized in the class system, namely the S1 class is a very appropriate level, the S2 class is the appropriate level and the S3 class is the inappropriate level. The analysis uses GIS method to get a map of the suitability of seawater quality parameters. Water quality parameter measurements in Jepara Regency waters get temperature data of 27.8-28. $6^{\circ} \mathrm{C}$, salinity of $35.0-37.3$ ppt brightness of $70-120 \mathrm{~cm}$ and Total Suspended Solid (TSS) of 48.60-64, $40 \mathrm{mg} / \mathrm{l}$. Along the coast of Jepara Regency, no one is included in the S1 class. The location of waters included in the S2 class of waters of Kedung Subdistrict, Tahunan Subdistrict, Keling Subdistrict and Donorojo Subdistrict. While the S3 class is in the waters of Jepara District, Mlonggo District, Bangsri District and Kembang District.

Keywords : Parameters, Physics, Waters, Aquaculture, Ponds, Jepara

\section{PENDAHULUAN}

Pengelolaan budidaya pantai memerlukan media berupa air laut dalam keadaan optimal sesuai dengan kondisi minimum yang dipersyaratkan untuk dapat tumbuh dan berkembanganya biota yang dibudidayakan (kultivan). Prinsip pengelolaan air pada kegiatan budidaya tambak adalah mempertahankan kualitas air pada kisaran parameter yang optimal bagi kehidupan kultivan serta menekan terjadinya fluktuasi parameter lingkungan yang tinggi (Mustofa, 2017). Taranamulia et al. (2015) menjelaskan bahwa data kuantitas air laut yang tersedia adalah untuk mendukung kegiatan budidaya sekaligus mengantisipasi beban limbah yang ditimbulkan merupakan informasi penting untuk penilaian awal daya dukung lahan untuk budidaya. Pemilihan lokasi yang tepat sesuai dengan karakteristik fisika lingkungan perairan memiliki peran yang sangat penting untuk keberhasilan usaha budidaya. Pengelolaan sumberdaya perikanan pantai/laut untuk mengimbangi pengelolaan perikanan tangkap secara spasial perlu adanya upaya penentuan kesesuaian kawasan untuk usaha budidaya perikanan sehingga mampu bersinergi dapat saling mendukung dan memberikan dampak positif terhadap penyediaan pangan kepada masyarakat (Adibrata et al, 2013). Faktor penting dalam usaha budidaya pantai adalah media berupa air laut 
yang sesuai dengan kebutuhan kultivan. Media air laut ini harus optimal parameternya antara lain suhu, salinitas kecerahan dan total padatan tersuspensi.

Kabupaten Jepara merupakan salah satu kabupaten di Jawa Tengah di mana sebagian masyarakatnya memiliki profesi sebagai petambak ikan dan udang dengan memanfaatkan potensi wilayah pesisir. Dari 16 kecamatan terdapat 8 kecamatan yang memiliki wilayah pesisir, yaitu Kecamatan Kedung, Tahunan, Jepara, Mlonggo, Bangsri, Kembang, Keling dan Donorojo. Total panjang pantai adalah $73 \mathrm{~km}$ dengan elevasi landai dan substrat pasir berlumpur, akses mudah dijangkau dan ketersediaan air tawar disuplai oleh sungai yang banyak bermuara di laut. Potensi ini sangat mendukung untuk digunakan sebagai media budidaya tambak.

Pendukung utama usaha tambak adalah ketersediaan air laut yang optimal untuk kelangsungan hidup dan pertumbuhan kultivan. Usaha budidaya perairan memerlukan informasi penting tentang parameter air laut sebagai daya dukung dan manajemen lingkungan. Beberapa parameter fisika perairan penting yang perlu diketahui tersebut adalah suhu, salinitas, kecerahan dan total padatan tersuspensi. Pengukuran parameter kualitas air laut dapat menunjukkan kesesuaian parameter air laut yang layak untuk usaha budidaya pantai di Kabupaten Jepara.

Penelitian ini bertujuan untuk mengetahui tingkat kesesuaian parameter perairan sebagai daya dukung usaha budidaya tambak di Kabupaten Jepara. Manfaat secara praktis adalah membangun kerangka pikir dan perumusan kebijakan dalam hal pengelolaan perikanan budidaya tambak di Kabupaten Jepara.

\section{MATERI DAN METODE}

Metode yang digunakan adalah metode survey, yaitu metode yang dilakukan untuk mendapatkan fakta dari gejala yang ada. Penelitian dilaksanakan pada bulan Juni 2019 dengan jumlah titik pengamatan sebanyak 10 buah di sepanjang pantai Kabupaten Jepara. Jarak antar titik pengamatan berkisar antara 500-700 m dan jarak titik pengamatan dengan pantai sekitar $500 \mathrm{~m}$. Penentuan titik pengamatan dilakukan secara purposive sampling dengan pertimbangan tertentu selain memudahkan juga mewakili daerah yang diteliti. (Hartoko dan Alexander, 2009). Lokasi penelitian dan titik stasiun pengambilan sampel sebagaimana dalam Gambar 1.

Karaketristik parameter fisika air laut terdiri dari suhu, salinitas, kecerahan dan TSS. Pengukuran parameter suhu, salinitas dan kecerahan dilakukan secara insitu menggunakan termometer, hand refraktormeter dan sechidisk. Sedangkan analisa TSS dilakukan dengan mengukur sampel air dari lokasi pengamatan dengan analisa sesuai prosedur pengukuran kandungan total zat padat tersuspensi berdasarkan SNI 06-6989.3-2004. Seluruh pengukuran parameter fisika air laut dilakukan pengulangan sebanyak 3 kali. 

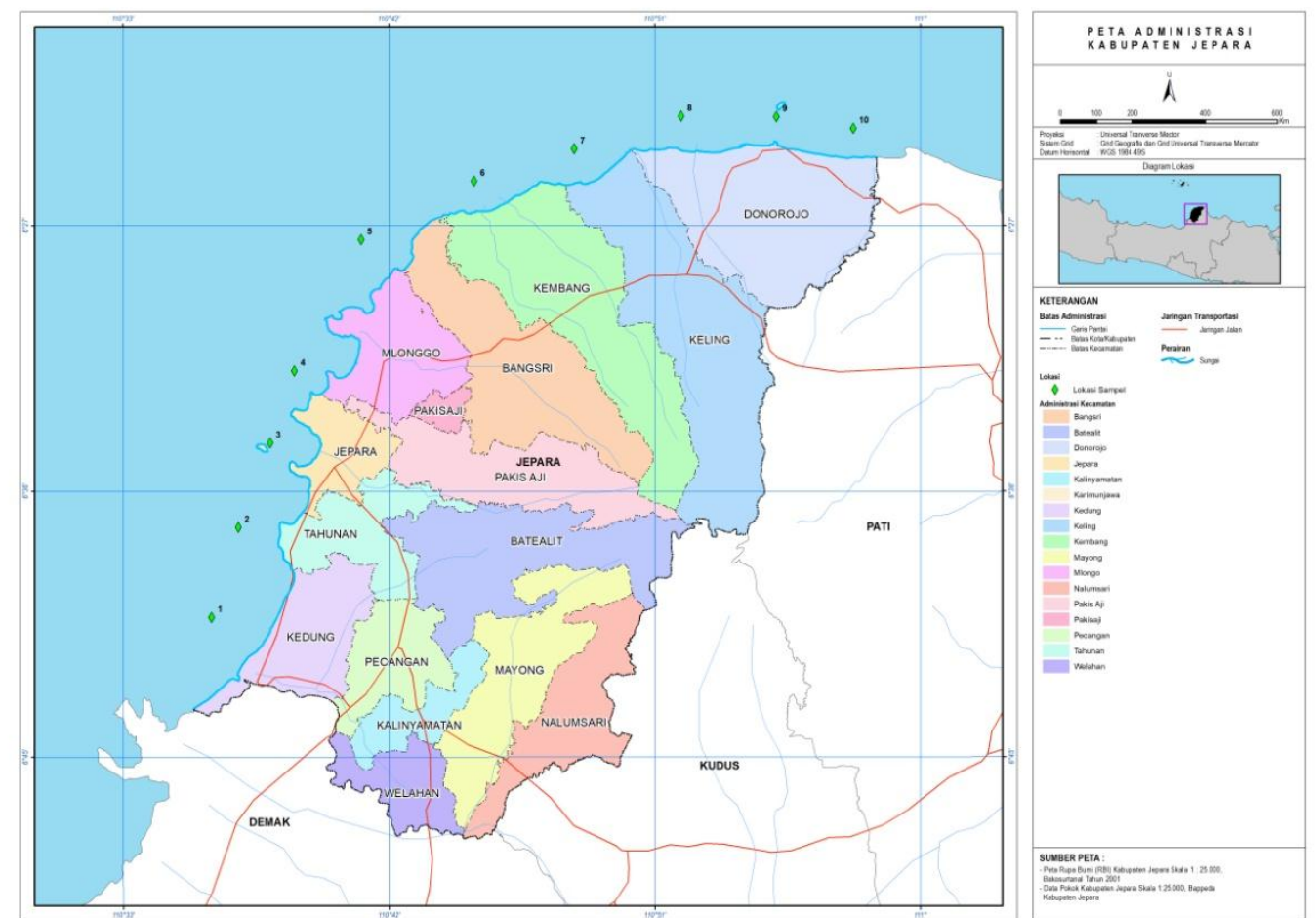

Gambar 1. Lokasi penelitian dan titik pengambilan sampel

Analisa kesesuaian parameter fisika air laut dengan membuat matrik kesesuaian dari parameter perairan yang diukur. Tingkat kesesuaian kualitas air dibagi atas 3 kelas yaitu sangat sesuai (S1), sesuai (S2) dan tidak sesuai (S3). Matrik bobot, kelas dan skor sebagaimana tersaji dalam Tabel 1 yang merupakan pembobotan dan penetapan nilai kesesuaian kualitas perairan yang mendukung budidaya tambak. Nilai masing-masing parameter di suatu titik lokasi penelitian diperoleh dari perkalian antara bobot dan nilai. Pemberian bobot didasarkan pada seberapa besar dampak yang diakibatkan oleh perubahan parameter tersebut terhadap kesesuaian parameter perairan untuk mendukung budidaya tambak. Penilaian kesesuaian perairan Kabupaten Jepara sebagaimana Tabel 2.

Kelas S1 adalah tingkat "sangat sesuai" di mana kondisi perairan sangat sesuai untuk mendukung upaya budidaya pantai dengan beberapa faktor pembatas yang tidak berarti untuk kelangsungan hidup dan laju sintasan kultivan budidaya. Kelas S2 adalah tingkat "sesuai" di mana kondisi perairan sesuai untuk menunjang kegiatan budidaya pantai tetapi terdapat beberapa parameter lingkungan yang menjadi pembatas terhadap kelangsungan hidup dan laju sintasan biota budidaya. Kelas S3 adalah tingkat "tidak sesuai", di mana kondisi perairan tidak sesuai untuk digunakan sebagai media budidaya karena memiliki faktor pembatas yang sangat besar. 
Tabel 1. Parameter perairan dengan bobot, kelas dan skor

\begin{tabular}{|c|c|c|c|c|c|c|c|c|}
\hline \multirow{2}{*}{ No } & \multirow{2}{*}{$\begin{array}{l}\text { Para- } \\
\text { meter }\end{array}$} & \multirow{2}{*}{$\begin{array}{l}\text { Bo- } \\
\text { bot }\end{array}$} & \multicolumn{2}{|l|}{ S1 } & \multicolumn{2}{|l|}{ S2 } & \multicolumn{2}{|l|}{ S3 } \\
\hline & & & Kelas & Skor & Kelas & Skor & Kelas & Skor \\
\hline 1 & $\begin{array}{l}\text { Suhu } \\
\left({ }^{\circ} \mathrm{C}\right)\end{array}$ & 25 & $\begin{array}{l}28 \\
30\end{array}$ & 5 & $\begin{array}{l}24-<28 \\
\text { atau } \\
>30-34\end{array}$ & 3 & $\begin{array}{l}<24 \\
\text { atau } \\
>34\end{array}$ & 1 \\
\hline 2 & $\begin{array}{l}\text { Salinitas } \\
(\% / \%)\end{array}$ & 25 & $\begin{array}{l}30 \\
33\end{array}$ & 5 & $\begin{array}{l}29 \text { atau } \\
>33-35\end{array}$ & 3 & $\begin{array}{l}<29 \\
\text { atau } \\
>35\end{array}$ & 1 \\
\hline 3 & $\begin{array}{l}\text { Kecera- } \\
\text { han } \\
(\mathrm{cm})\end{array}$ & 25 & $\begin{array}{l}30 \\
50\end{array}$ & 5 & $\begin{array}{l}20-<30 \\
\text { atau } \\
50-<70\end{array}$ & 3 & $\begin{array}{l}<30 \\
\text { atau } \\
>70\end{array}$ & 1 \\
\hline 4 & $\begin{array}{l}\text { TSS } \\
(\mathrm{mg} / \mathrm{l})\end{array}$ & 25 & $\begin{array}{l}150 \\
200\end{array}$ & 5 & $\begin{array}{l}100 \\
<150 \\
\text { atau } \\
200-< \\
250\end{array}$ & 3 & $\begin{array}{l}<100 \\
\text { atau } \\
>250\end{array}$ & 1 \\
\hline & $\begin{array}{l}\text { Bobot x } \\
\text { skor }\end{array}$ & 100 & & 500 & & 300 & & 100 \\
\hline
\end{tabular}

Sumber : Modifikasi dari Sunyoto (1997) dalam Adibrata dkk (2013),

Permen KP No. 75/PERMEN-KP/2016,

Ratnawati dan Indrajaya (2012)

Perhitungan bobot dikalikan skor adalah nilai yang menjelaskan kelas dari masing-masing lokasi berdasarkan karakteristik parameter kualitas air. Analisis kesesuaian lahan dari parameter perairan yang terukur sesuai kelasnya dirinci dalam Tabel 2.

Tabel 2. Kelas kesesuaian lahan perairan

\begin{tabular}{lll}
\hline No & Analisis kesesuaian lahan & Kelas \\
\hline 1 & Sangat sesuai (S1) & $450-500$ \\
2 & Sesuai (S2) & $300-440$ \\
3 & Tidak sesuai (S3) & $100-290$ \\
\hline
\end{tabular}

Data kualitas air hasil dari pengukuran yang dilakukan pada setiap parameter di titik-titik lokasi penelitian yaitu suhu, salinitas, kecerahan dan TSS diolah menggunakan software ArcGis 10.0 untuk memperoleh gambaran peta tematik parameter kualitas air laut.

\section{HASIL DAN PEMBAHASAN}

Hasil pengukuran parameter kualitas air di sepanjang pantai Kabupaten Jepara disajikan dalam Tabel 3. 
Tabel 3. Hasil pengukuran parameter kualitas air Kabupaten Jepara

\begin{tabular}{llllll}
\hline Titik & Koordinat & $\begin{array}{l}\text { Suhu } \\
\left({ }^{\circ} \mathrm{C}\right)\end{array}$ & $\begin{array}{l}\text { Salinitas } \\
(\mathrm{ppt})\end{array}$ & $\begin{array}{l}\text { Kecerahan } \\
(\mathrm{cm})\end{array}$ & $\begin{array}{l}\text { TSS } \\
(\mathrm{mg} / \mathrm{l})\end{array}$ \\
\hline 1 & $-6.671167,110.599904$ & 28,0 & 35,0 & 70,0 & 64,40 \\
2 & $-6.620356,110.615181$ & 27,8 & 35,0 & 70,0 & 55,20 \\
3 & $-6.572779,110.633034$ & 27,9 & 37,3 & 100,0 & 48,60 \\
4 & $-6.532191,110.646767$ & 27,9 & 37,0 & 100,0 & 49,85 \\
5 & $-6.457997,110.684533$ & 28,4 & 36,0 & 120,0 & 50,20 \\
6 & $-6.425076,110.748219$ & 28,5 & 36,0 & 100,0 & 51,25 \\
7 & $-6.406823,110.804696$ & 27,9 & 35,0 & 90,0 & 60,40 \\
8 & $-6.388399,110.865120$ & 28,6 & 35,0 & 80,0 & 64,20 \\
9 & $-6.388740,110.918850$ & 27,9 & 35,3 & 80,0 & 53,40 \\
10 & $-6.395393,110.962109$ & 28,0 & 35,0 & 85,0 & 52,55 \\
\hline
\end{tabular}

Berdasarkan Tabel 3 dapat dijelaskan bahwa suhu perairan Kabupaten Jepara berkisar antara $27,8-28,6^{\circ} \mathrm{C}$. Suhu terendah pada titik 2 yaitu di perairan Desa Semat Kecamatan Tahunan sebesar $27,8^{\circ} \mathrm{C}$ sedangkan tertinggi pada titik 8 yaitu di perairan Kecamatan Keling sebesar $28,6^{\circ} \mathrm{C}$. Salinitas terendah sebesar 35,0 ppt pada titik 1,2,7,8 dan 10 yaitu di perairan Kedung, Tahunan, Kembang, Keling dan Donorojo. Sedangkan salinititas tertinggi sebesar 37,3 ppt di titik 3 yaitu di perairan sekitar Pulau Panjang Kabupaten Jepara. Kecerahan perairan Kabupaten Jepara berkisar antara 70-120 cm. Kecerahan terendah sebesar $70 \mathrm{~cm}$ di titik 1 dan 7 yaitu di perairan Kecamatan Kedung dan Kecamatan Kembang. Sedangkan kecerahan tertinggi sebesar $120 \mathrm{~cm}$ pada titik 5 yaitu di periaran Kecamatan Mlonggo. Total Suspended Solid (TSS) perairan Kabupaten Jepara berkisar antara 48,60-64,40 mg/l. Terendah sebesar 48,60 mg/l pada titik 3 yaitu di perairan Pulau Panjang Kabupaten Jepara dan tertinggi sebesar $64,40 \mathrm{mg} / \mathrm{l}$ pada titik 1 yaitu di perairan Kecamatan Kedung.

\section{Analisis Parameter Kualitas Air Laut}

\section{Suhu}

Suhu perairan sangat mempengaruhi keadaan kualitas air secara keseluruhan. Suhu yang tinggi menyebabkan ikatan kovalen senyawa air menjadi renggang yang memungkinkan terjadinya pelepasan oksigen ke udara, sehingga oksigen terlarut (dissolved oxygen) akan menurun. Laju reaksi kimia dalam air akan meningkat 2 kali setiap kenaikan suhu $10^{\circ} \mathrm{C}$. Amonia juga akan meningkat jika suhunya naik. Keadaan ini sangat berpengaruh terhadap budidaya perikanan, karena menurut Effendi (2003) ikan merupakan hewan poikiloterm (berdarah dingin) sehingga metabolisme tubuh ikan tergantung pada suhu lingkungannya. Suhu perairan pada titik lokasi penelitian menunjukkan besaran $27,8-28,6^{\circ} \mathrm{C}$. Nilai ini menjadi pembatas pada daya dukung kesesuaian kualitas perairan untuk tambak, karena suhu perarian yang sangat sesuai untuk 
budidaya tambak adalah air laut bersuhu $28-30^{\circ} \mathrm{C}$ (Adibrata dkk, 2013; Permen KP No. 75/PERMEN-KP/2016; Ratnawati dan Indrajaya, 2012). Besaran suhu terukur pada tiap stasiun pengamatan sebagaimana Gambar 2.

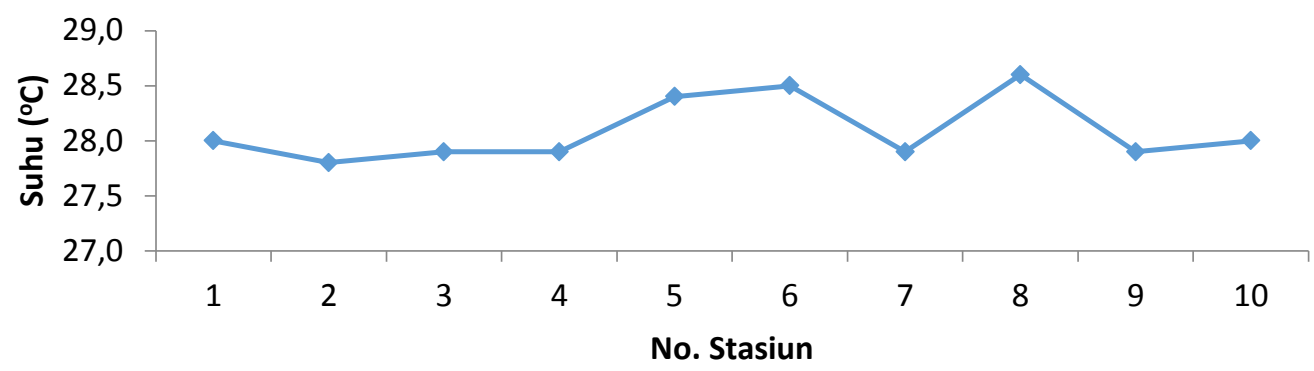

Gambar 2. Besaran suhu terukur tiap stasiun pengamatan

Berdasarkan analisa peta tematik suhu pearairan di sepanjang pantai Kabupaten Jepara disajikan dalam Gambar 3.

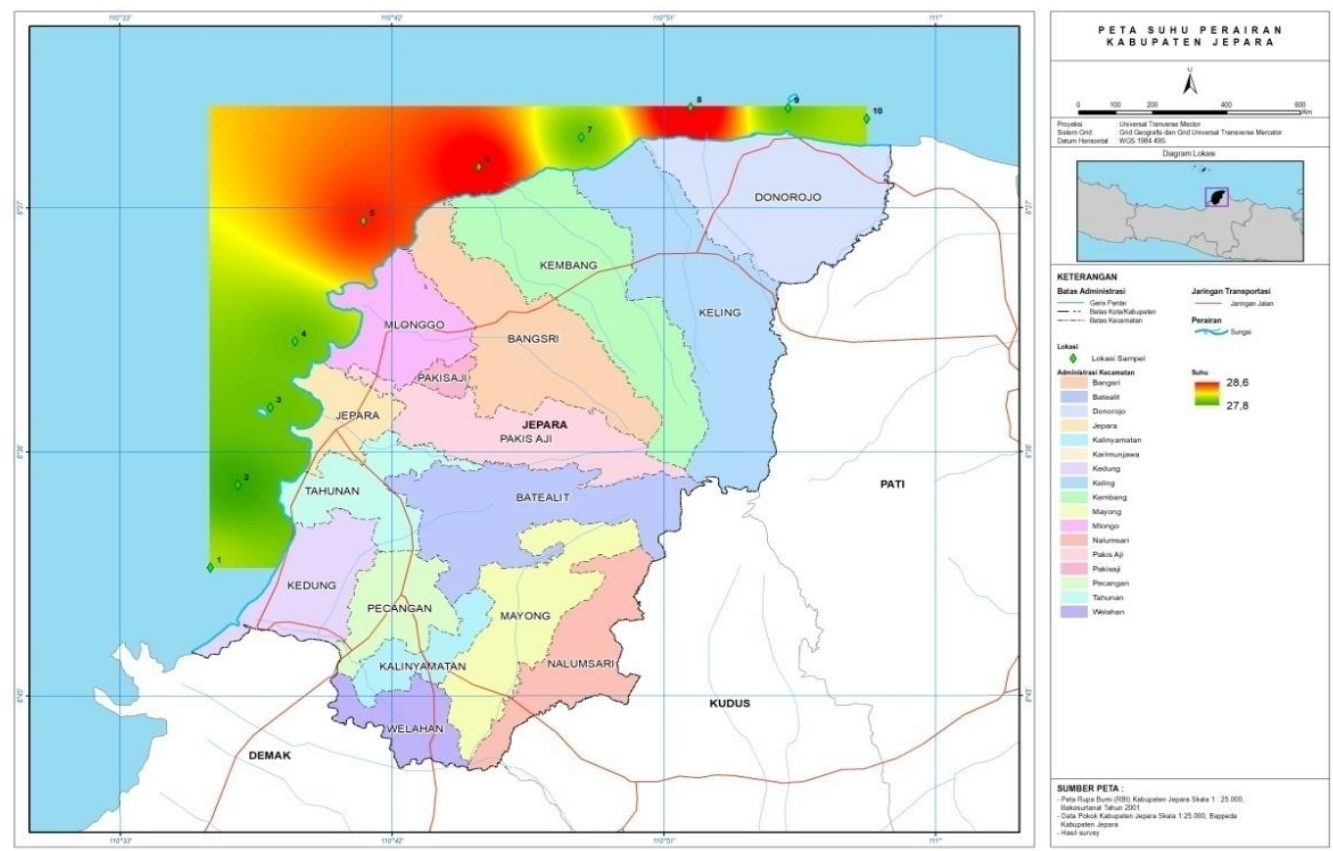

Gambar 3. Peta sebaran suhu di perairan pantai Kabupaten Jepara

\section{Salinitas}

Salinitas perairan yang didapatkan dari hasil pengukuran menunjukkan besaran antara $35-37,3$ ppt. Salinitas 35 ppt berada pada titik 1, 2, 7, 8, 9 dan 10 yaitu di perairan Kedung, Tahunan, Keling dan Donorojo. Menurut Akib (2015) perbedaan salinitas menunjukkan adanya beberapa faktor yaitu sirkulasi air laut, penguapan, curah hujan dan aliran sungai. Faktor penting yang menjadi pengaruh terhadap salinitas dari 
lokasi sepanjang pantai Kabupaten Jepara adalah sirkulasi air laut yang disebabkan oleh gelobang akibat besarnya angin timur pada saat pengukuran dilakukan. Nilai salinitas menunjukkan pada tingkat sesuai (S2) untuk enam titik ini. Sedangkan titik lainnya menunjukkan ketidak sesuaiannya (S3) karena salinitasnya berada di atas 35 ppt. Grafik salinitas sebagaimana dalam Gambar 4.

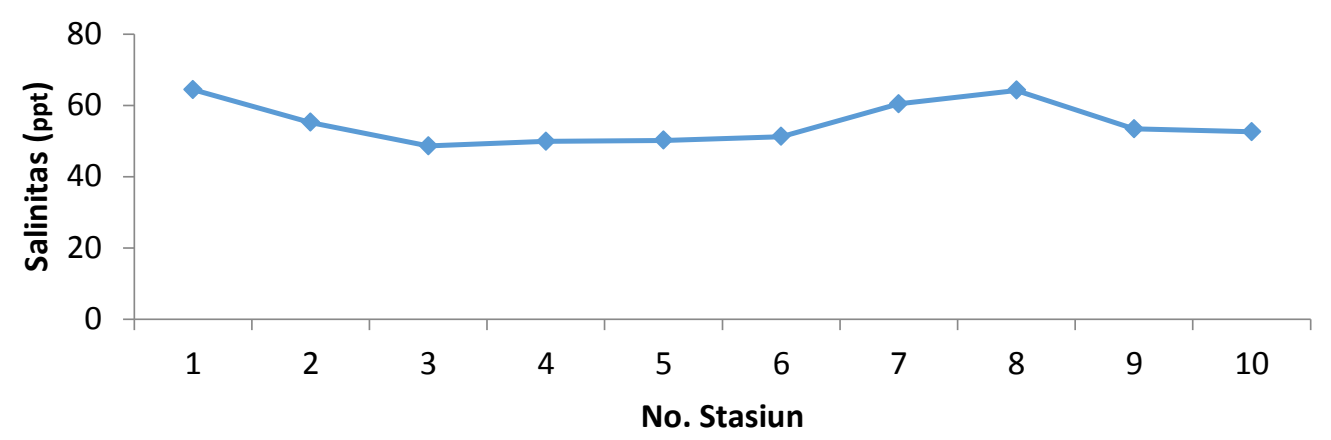

Gambar 4. Besaran salinitas terukur tiap stasiun pengamatan
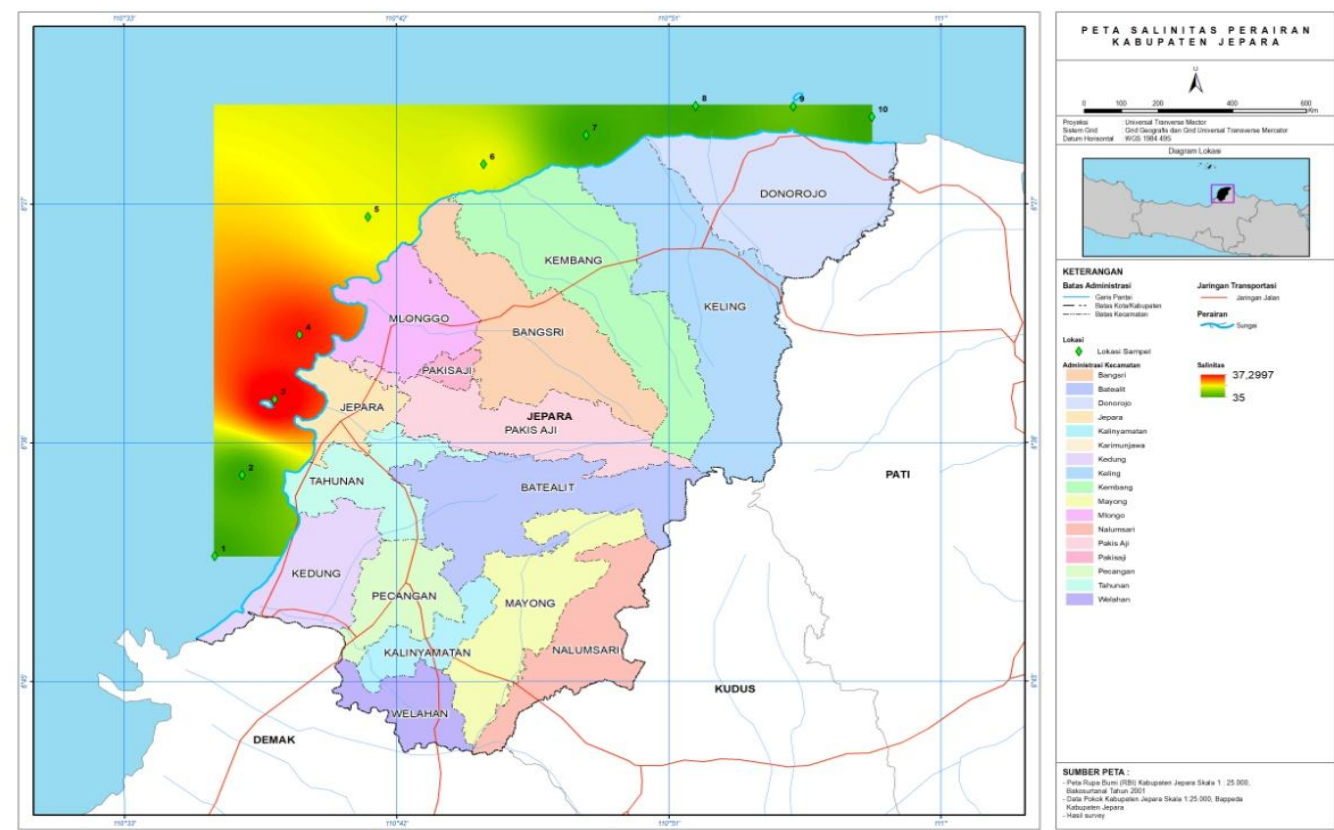

Gambar 5. Peta sebaran salinitas di perairan pantai Kabupaten Jepara

\section{Kecerahan}

Kecerahan perairan dipengaruhi oleh kedalaman perairan, substansi sedimen, kecepatan arus dan waktu pengamatan. (Akib, 2015). Kecerahan berkaitan dengan kedalaman penetrasi sinar matahari menemus kolom air, sebagaimana Hutabarat (2000) menjelaskan bahwa cahaya matahari akan semakin berkurang intensitasnya seiring dengan kedalaman. Sedangkan menurut Effendi (2003) pemantulan cahaya mempunyai intensitas yang bervariasi menurut sudut datang cahaya 
tersebut. Grafik kecerahan pada perairan pantai Kabupaten Jepara sebagaimana dalam Gambar 6.

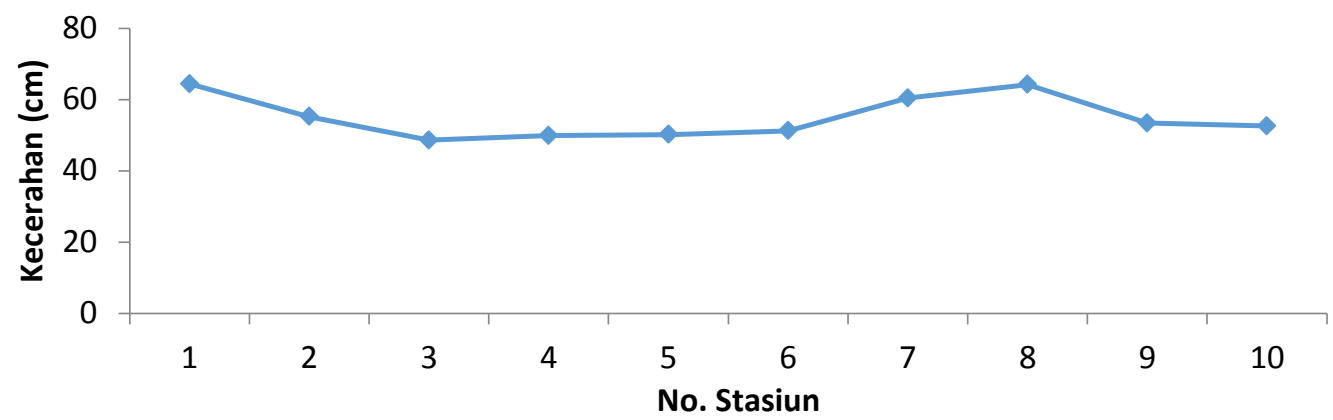

Gambar 6. Besaran kecerahan yang terukur tiap stasiun pengamatan

Berdasarkan Tabel 1, kecerahan perairan pantai Kabupaten Jepara yang masuk kelas sesuai adalah adalah titik 1 dan 2, 8, 9 dan 10 yaitu di perairan pantai Kecamatan Kedung, Tahunan, Keling dan Donorojo yaitu pada kedalaman $70-80 \mathrm{~cm}$. Sedangkan pada titik lainnya antara $90-$ $100 \mathrm{~cm}$ yang masuk pada kelas tidak sesuai. Peta sebaran kecerahan perairan pantai Kabupaten Jepara sebagaimana Gambar 7.
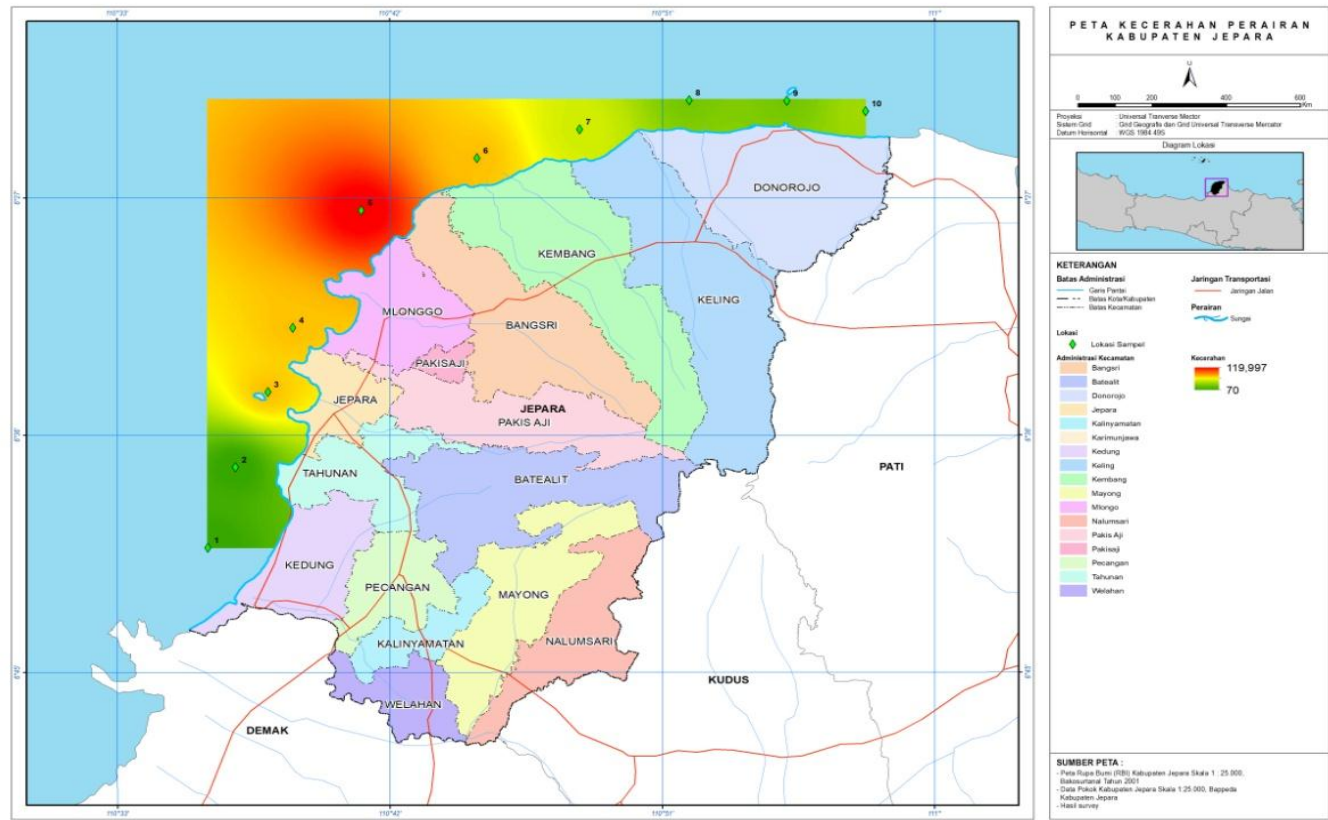

Gambar 7. Peta sebaran kecerahan di perairan pantai Kabupaten Jepara

Total Padatan Tersuspensi (Total Suspended Solid / TSS)

Pengukuran total padatan tersuspensi (Total Suspended Solid/TSS) pada perairan pantai Kabupaten Jepara seluruhnya berada pada nilai kurang dari $100 \mathrm{mg} / \mathrm{l}$. Nilai ini menunjukkan bahwa pada seluruh titik pengamatan berada pada kondisi tidak sesuai jika merunut pada Tabel 1. 
Pada tabel tersebut dinyatakan bahwa kelas sangat sesuai adalah 150 $200 \mathrm{mg} / \mathrm{l}$ dan kelas sesuai pada nilai antara 100-<150 mg/l atau $200-<250$ $\mathrm{mg} / \mathrm{l}$. Grafik hasil pengukuran TSS di perairan pantai Kabupaten Jepara sebagaimana Gambar 8.

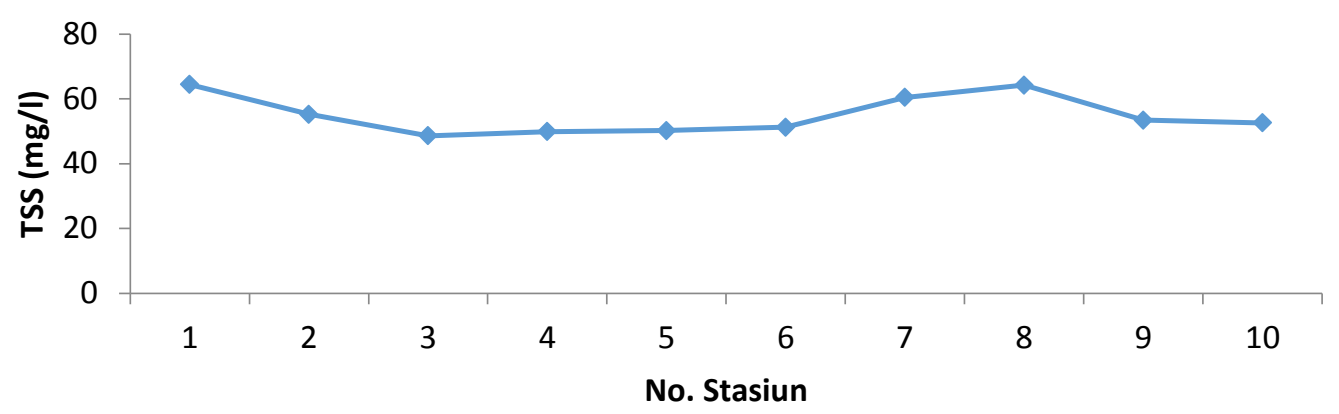

Gambar 8. Besaran TSS yang terukur tiap stasiun pengamatan

Total padatan tersuspensi adalah seluruh zat padat baik pasir, lumpur maupun tanah liat atau partikel-partikel yang tersuspensi dalam air laut, lainnya adalah komponen biotik contohnya fitoplankton, zooplanton, bakteri atau komponen abiotik contohnya detritus dan partikel-partikel endapan lainnya. (Permana et al, 1994). Nilai padatan tersuspensi perairan dipengaruhi oleh komposisi material dasar dan pergerakan massa air terhadap substrat (Akib, 2015). Sedangkan Polprasert (2009) menjelaskan bahwa TSS merupakan salah satu parameter pencemaran yang harus diketahui dalam usaha budidaya tambak, karena sebanyak $35 \%$ jumlah pakan yang diberikan ke kultivan akan masuk ke perairan dalam bentuk TSS. Peta sebaran TSS di perairan pantai Kabupaten Jepara sebagaimana Gambar 9.

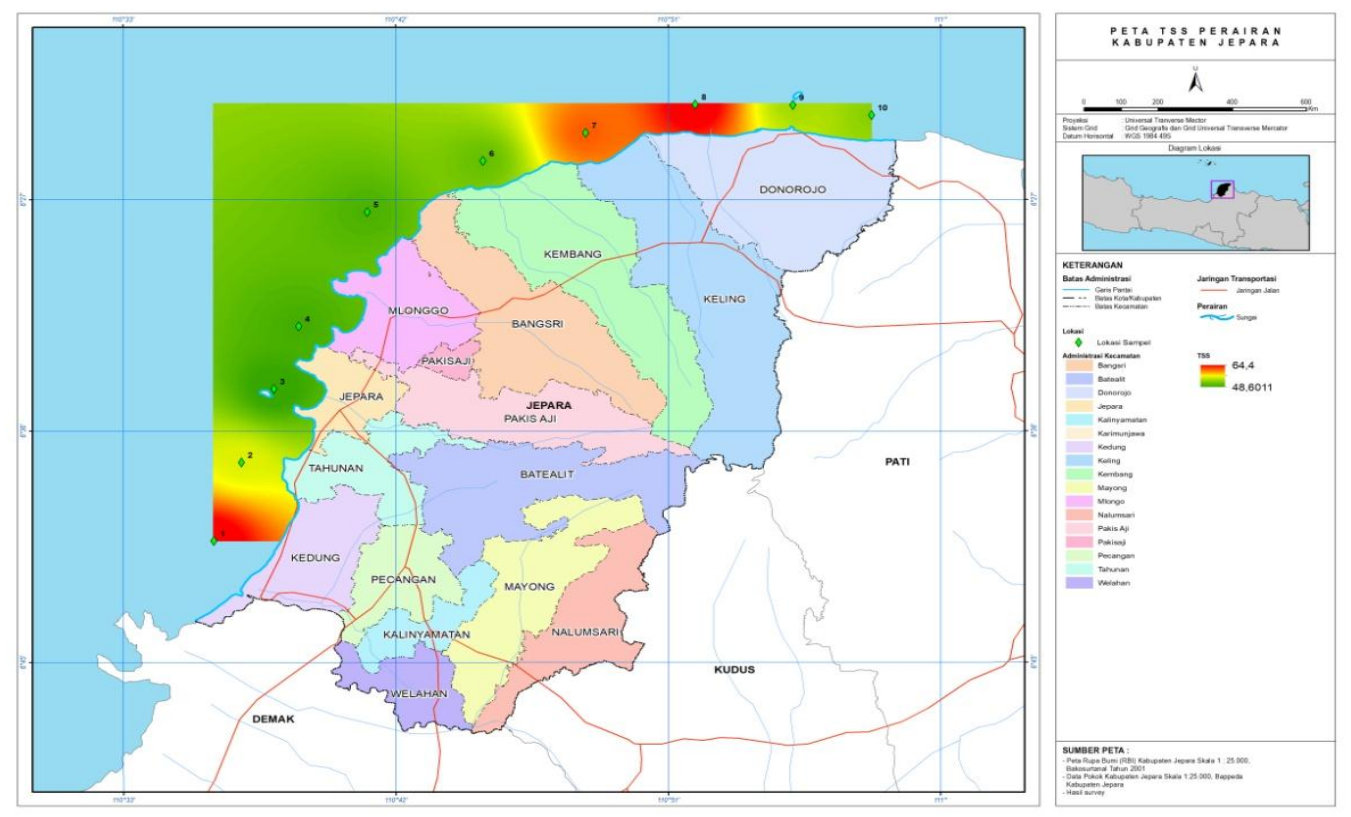

Gambar 9. Peta sebaran TSS di perairan pantai Kabupaten Jepara 


\section{Analisis Kesesuaian Lahan}

Hasil pembobotan berdasarkan pada Tabel 1 dan Tabel 2 menunjukkan bahwa kondisi perairan Kabupaten Jepara masuk dalam kelas S2 yaitu sesuai dan S3 tidak sesuai. Peta kesesuaian lahan berdasarkan kualitas parameter air laut sebagaimana Gambar 10.
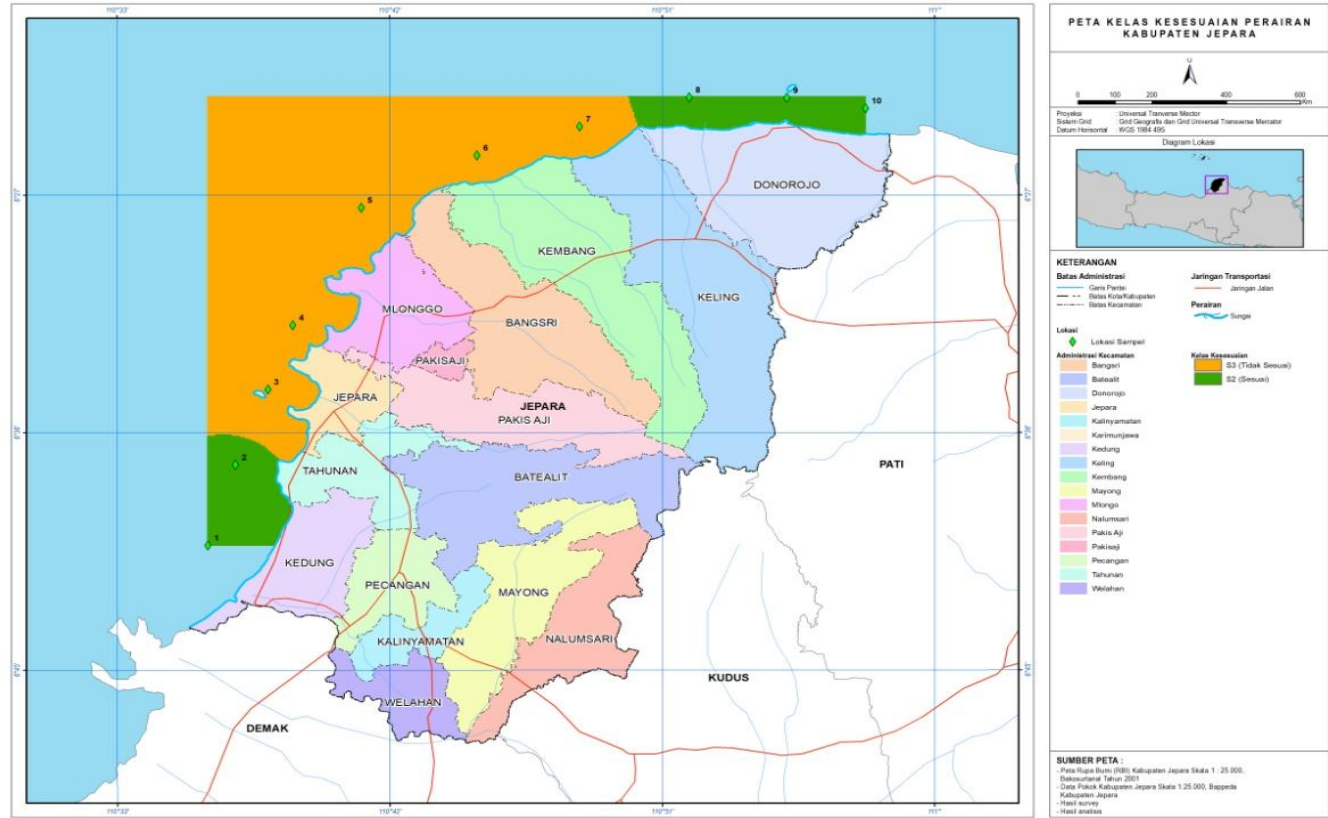

Gambar 10. Peta kesesuaian lahan berdasarkan parameter kualitas air laut di pantai Kabupaten Jepara

Lokasi yang masuk dalam kelas S2 adalah titik 1, 2, 8, 9 dan 10. Titik ini berada pada perairan Desa Kedungmalang Kecamatan Kedung, Desa Semat Kecamatan Tahunan, Kecamatan Keling dan Kecamatan Donorojo. Pada lokasi ini kondisi perairan sesuai untuk menunjang kegiatan budidaya pantai tetapi terdapat beberapa parameter lingkungan yang menjadi pembatas terhadap kelangsungan hidup dan laju sintasan biota budidaya. Pada kelima perairan ini memiliki karakteristik parameter suhu $27,8-28,6^{\circ} \mathrm{C}$, salinitas sekitar 35,0 ppt, pH 6,9-7,0, kecerahan 70-80 $\mathrm{cm}$ dan TSS 52,55-64,40 mg/l. Kondisi parameter ini terdapat di Kecamatan Kedung dan Tahunan yang berada di sebelah selatan wilayah perairan Kabupaten Jepara dan Kecamatan Keling dan Donorojo yang berada di wilayah perairan utara Kabupaten Jepara. Lokasi ini berbatasan dengan Kabupaten Demak di sebelah selatan dan Kabupaten Pati di sebelah utara.

Lokasi yang masuk dalam kelas S3 adalah titik 3, 4, 5, 6 dan 7 yaitu di perairan Pulau Panjang Jepara, Bandengan Jepara, Mororejo Mlonggo, Kecamatan Bangsri dan Kecamatan Kembang. Pada lokasi ini kondisi perairan tidak sesuai untuk digunakan sebagai media budidaya karena memiliki faktor pembatas yang sangat besar. Pada kelima perairan ini memiliki karakteristik parameter suhu $27,9-28,5^{\circ} \mathrm{C}$, salinitas $35,0-37,3 \mathrm{ppt}$, 
kecerahan 90-120 cm dan TSS 48,60-60,40 mg/l. Parameter terukur yang menjadi pembatas adalah salinitas dan kecerahan. Kedua parameter ini berada pada kelas tidak sesuai berdasarkan pada Tabel 1 di mana nilai salinitas yang sangat sesuai adalah 30 - 35 ppt dan nilai kecerahan yang sangat sesuai adalah $30-50 \mathrm{~cm}$.

\section{KESIMPULAN}

Berdasarkan hasil penelitian maka disimpulkan bahwa hasil identifikasi terhadap parameter fisika oseanografi di perairan pantai Kabupaten Jepara menunjukkan nilai yang berbeda pada tiap titik stasiun pengamatan. Hasil analisis kesesuaian perairan bagi usaha budidaya tambak udang di Kabupaten Jepara menunjukkan bahwa perairan kecamatan Kedung, Tahunan, Keling dan Donorojo berada pada kategori sesuai (titik 1, 2, 8, 9 dan 10). Sedangkan pada peraian pantai Kecamatan Jepara, Mlonggo, Bangsri dan Kembang (titik 3, 4, 5, 6 dan 7) berada pada kategori tidak sesuai.

\section{DAFTAR PUSTAKA}

Adibrata, S., M. Mukhlis K. dan Fredinan Y. 2013. Daya Dukung Lingkungan Untuk Budidaya Kerapu (Famili Serranidae) di Perairan Pulau Pongok Kabupaten Bangka Selatan. Jurnal Pesisir dan Pulau-Pulau Kecil. Vo. 2 No. 1, Juli 2013 : 43-58.

Akib, A., Magdalena L, Ambeng dan Muhtadin A. 2015. Kelayakan Kualitas Air Untuk Kawasan Budidaya Eucheuma cottoni Berdasarkan Aspek Fisika, Kimia dan Biologi di Kabupaten Kepulauan Selayar. Jurnal Pesisir dan Laut Tropis. Vol. 1 No. 1 Tahun $2015: 25-36$.

Effendi, H. 2003. Telaah Kualitas Air Bagi Pengolahan Sumberdaya Hayati Lingkungan Perairan. Kanisius. Yogyakarta.

Hartoko, A. dan Alexander K. 2009. Spasial Modeling for Marine Culture Site Selection Based on Ecosystem Parametrs at Kupang Bay, East Nusa Tenggara-Indonesia. Int. J. Remote Sensing Earth Science, 6:57-64.

Hutabarat, S. 2000. Peranan Kondisi Oceanografi terhadap Perubahan Iklim, Produktivitas dan Distribusi Biota Laut. UNDIP, Semarang.

Mustofa, A. 2017. Kandungan Total Zat Padat Tersuspensi Dari Outlet Tambak Udang Intensif di Kabupaten Jepara. Jurnal Disprotek, Vol. 8 No. 1 Januari 2017. Hal. $34-45$. 
Pantjara, B., Utoji, Aliman dan Markus M. 2008. Keseuaian Lahan Budidaya Tambak di Kecamatan Watubangga Kabupaten Kolaka, Sulawesi Tenggara. J. Ris. Akuakultur Vol. 3 No. 1 Tahun 2009 : $123-135$.

Peraturan Menteri Kelautan dan Perikanan RI No. 75/PERMEN-KP/2016 tentang Pedoman Umum Pembesaran Udang Windu (Penaeus monodon) dan Udang Vaname (Litopenaeus vannamei).

Permana, S.D., E. Triyati, \& A. Nontji. 1994. Pengamatan Klorofil dan Seston di Perairan Selat Malaka 1978-1980: Evaluasi Kondisi Perairan Selat Malaka 1978-1980. Hal. 63.

Polprasert, C. 2009. Organic Waste Recycling. John Wey Sons. Toronto. Singapore.

Ristiyani, D. 2012. Evaluasi Kesesuaian Lahan untuk Budidaya Perikanan Tambak di Pesisir Kendal. Jurnal Geo Image 1 (1) (2012) : 12-18.

Ratnawati, E dan A. Indrajaya A. 2012. Daya Dukung Lingkungan Tambak di Kecamatan Pulau Derawan dan Sambaliung, Kabupaten Berau, Provinsi Kalimantan Timur. Jurnal IImiah Perikanan dan Kelautan. Vo. 4 No. 2, November 2012 : 175 - 185.

Tarunamulia, Hasnawi, Rezki A. S., Akhmad M., dan Mudian P. 2015. Perspektif Pengembangan Perikanan Budidaya Berdasarkan Karakteristik Pantai di Teluk Gerupuk dan Teluk Bumbung Kabupaten Lombok Tengah Provinsi Nusa Tenggara Barat. Jurnal Riset Akuakultur Vol. 10 No. 1 Th. 2015. Hal. 117-126. 